\title{
Effect of maternal exposure to octylphenol (4-tert-octylphenol) on the growth of the adrenal gland in male albino rats
}

\author{
Nafisa Mohamed Batarfi \\ Faculty of Science for Girls, King Abdulaziz University, Jeddah, Saudi Arabia \\ Email: Sala201018@gmail.com
}

Received 21 September 2011; revised 5 November 2011; accepted 16 November 2011

\begin{abstract}
4-tert-octylphenol (OP) is environmental pollutants that have been shown widespread impact estrogenic and toxic to the cells of mammals in culture. The effects of OP on the reproductive system of adult male vertebrates especially humans are virtually unknown. Thus, in the present investigation, pregnant females of albino rats were orally treated during pregnancy and until 21 days after birth (the period of lactation) with octylphenol (OP) at doses 0 (vehicle: corn oil), 40 $\mathrm{mg} / \mathrm{kg}$ and $120 \mathrm{mg} / \mathrm{kg}$ on the epididymis of male rats at puberty (12 weeks of age). The present result showed that there is non-significant in the number; the size of newborn rats and there increased in mortality rate of newborn rats of the pregnant female treatment with dose low-and high-octylphenol compared to the control group. there is increased in the average body weight and percentage of gain in body weight of male rats from mothers of small treatment (G2, G3) and the control group (G1) for 12 weeks of age. Also, histological results showed that the adrenal gland in the group which was given high dose of octylphenol (G3) show that Severe histological changes in the cortex. When examining medulla and found large areas of necrosis and cell degradation, necrosis and cell death sharply.
\end{abstract}

Keywords: 4-Tert-Octylphenol (OP); Swiss Albino Rats; Environmental Pollutants

\section{INTRODUCTION}

An environmental pollutant, 4-tert-octylphenol (OP) [p-(1,1,3,3-tetramethylbutyl)-phenol], an endocrine-disrupting chemical, is an alkylphenolic compound derived as one of the major biodegradation products of nonionic surfactants, alkylphenol polyethoxylates (APEOs). These APEOs are released to the environment from the use of many chemicals such as detergents, paints, plastics, herbicides, and pesticides, and have become a major component in wastewater systems [1,2]. Because of large quantities of alkylphenols are manufactured every year to provide substrate for the production of APEOs, they continue to contaminate the environment along with their respective alkylphenols. OP shows marked similarities to that of natural estrogens [2,3] and has been known to have a higher estrogenic potency compared with other alkylphenols of the same class of chemicals [4].

Chemicals in the environment exhibiting hormone-like activities have gained considerable attention during recent years, because of their ability to disrupt processes governed by hormones. The reproductive system seems to be especially vulnerable and, in connection with abnormally high exposures of such hormone disruptors, reproductive processes in animals, e.g. alligators, may be affected [5]. Moreover, hormone disruptors in the environment may also affect the reproductive system in humans [6].

The infertility is a sad reality, male reproductive health have changed to the worse during the last forty year as has been reported from different countries, the global decline in sperm characteristics which represents a decline in the number of sperm and volume in men [7-12]. And where it is known that the natural functions of all organs of the body regulated by hormones secreted by the endocrine system, the disturbances simple functions and especially during the critical stages of the life cycle such as configuration development and pregnancy gestation and lactation will lead to severe damage and longterm effects on those organs in animals land and rights $[9,12,13]$.

Therefore the current study aimed to study the effect of 4-tert-octylphenol on the pregnant female rats during pregnancy and lactation. The study included record changes and behavioral and morphological change in body weight of newborn rats of the pregnant female treatment with 4-tert-octylphenol and study the histological changes 
in adrenal glands of these newborn rats.

\section{MATERIALS AND METHODS}

\subsection{Experimental Animals}

The experimental animals used in this study were adult male (age two months) and female (Pregnant females). Swiss albino rats, (90 - 100 g) which were obtained from the animal house at King Fahd Medical Research Centre of King Abdul Aziz University in Jeddah. They were supplied with food and water ad libitum under standard conditions of light, humidity and temperature $\left(22^{\circ} \mathrm{C}-25^{\circ} \mathrm{C}\right)$.

\subsection{Chemicals}

4-tert-octylphenol (OP) is one of the environmental pollutants. The previous studies, which indicated that 4-tertoctylphenol has impact estrogenic action and anti-androgen, causing an adverse impact on the reproductive system of living organisms [14,4,15].

\section{Chemical Name and Formula}

4-(1,1,3,3-tetramethylbutyl) phenol or 4-(tert-octylphenol).

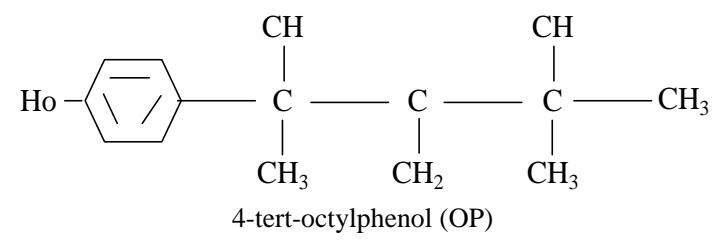

\subsection{Dosing and Treatment}

On the basis of previous studies were selected doses of 4-tert-octylphenol (OP) for the treatment of rats in the current study are low dose ( $40 \mathrm{mg} / \mathrm{kg}$ of body weight) and high dose $(120 \mathrm{mg} / \mathrm{kg}$ of body weight). In the current study, doses of OP were given to rats by oral gavages using Stomach tubes and calculate the dose for each rat according to the weight on treatment and to the specified period of the experiment. The treatment was daily. Corn oil has been used as a solvent for OP, where is the solvent record standard vehicle in toxicity studies at the administration of oral [16]. Heating the solution has been the record for the completion of the thawing process by mitigating the concentration required.

\subsection{Experiments Design}

30 of the Pregnant female rats which was divided into three groups, each consisting of ten rats as follows: The first group as control (G1) was given the solvent to the extent the user with doses in the treatment groups with the same size according to body weight to rats and at the same time (morning). Second group (G2) treated with low dose of OP of $40 \mathrm{mg} / \mathrm{kg}$ of body weight. The third group (G3) that was treated in a high dose of OP of 120 $\mathrm{mg} / \mathrm{kg}$ of body weight.

\subsection{Histological Study}

The adrenal gland of rat from each animal from treated and control have been cut into small parts and immersed in $10 \%$ buffered formalin solution and Each part of adrenal gland tissues were kept in separate numbered small glass bottles and they were then embedded in paraffin, and sectioned. Four sections (5 microns in thickness) were taken from each adrenal gland tissues from the control and treatment, each section being at a distance of at least $500 \mathrm{u}$ from the proceeding one sections were stained with haematoxylin and eosin [17].

\section{RESULT}

\subsection{The Impact of Treatment of Maternal Rats during Pregnancy and Lactation with Octylphenol (OP) on the Epididymis of Male Rats at Puberty}

\subsubsection{Viability}

The results obtained from Table 1 showed that there is non-significant in the number and the size of newborn rats of the pregnant female treatment with dose low-and high-4-tert-octylphenol compared to the control group and did not observe any superficial changes or behaveioral on newborns male rats during the period of infancy through adulthood.

\subsubsection{Mortality}

The present result present in Table 2 showed that there significantly $(P>0.05)$ increased in mortality rate of newborn rats of the pregnant female treatment with dose low-and high 4-tert-octylphenol (during the period of lactation). This increased is $17.3 \%$ and $24.7 \%$, respectively compared with control (7.3\%).

\subsubsection{Change in Body Weight}

The data in Table 3 show that the average body weight and percentage of gain in body weight of male rats from mothers of small treatment (G2, G3) and the control group (G1) for 12 weeks of age In respect to the weight of newborn rats $\left(\mathrm{PND}_{1}\right)$. There is significant increase in Average body weight of male newborn rats with control group (G1) gradually during the experiment and up after weaning (PND22) to $21.9 \pm 0.6 \mathrm{~g}$ and $90.7 \pm 11.2 \mathrm{~g}$ at the end of the experiment (12 weeks) and the rate of acquisition in weight $106.9 \%$ after weaning and $757 \%$ by the end of the probationary period for the weight of newborn rats $(10.6 \pm 0.9 \mathrm{~g})$.

In the group (G2) treatment with low dose. There is 
Table 1. Number and length (mean \pm SD) of newlyborn rats $\left(\mathrm{PND}_{1}\right)$ from control and treated groups of pregnant females.

\begin{tabular}{ccc}
\hline Animal groups & $\begin{array}{c}\text { Number of litter } \\
\text { (range, mean } \pm \text { SD) }\end{array}$ & $\begin{array}{c}\text { Body weight (gm) at } \\
\text { birth (PND })\end{array}$ \\
\hline Control G1 & $8-13$ & $8.6-14.4$ \\
$n=10$ & $10.4 \pm 0.5$ & $10.6 \pm 0.8$ \\
Low dose G2 & $8-12$ & $8.4-11.2$ \\
$n=10$ & $9.6 \pm 1.1$ & $9.8 \pm 0.9$ \\
High dose G3 & $6-12$ & $6.5-11.1$ \\
$n=10$ & $8.04 \pm 1.74$ & $8.5 \pm 1.6$ \\
\hline
\end{tabular}

$n$ : number of pregnant females.

Table 2. Percentage mortality of pups during $\mathrm{PND}_{1}$ through $\mathrm{PND}_{2}$ from control and treated pregnant females.

\begin{tabular}{cccc}
\hline \multirow{2}{*}{ Animal groups } & Number & \multicolumn{2}{c}{ Mortality } \\
\cline { 3 - 4 } & & number & \% \\
\hline Contol $\left(\mathrm{G}_{1}\right)$ & 96 & 7 & 7.3 \\
Low dose $\left(\mathrm{G}_{2}\right)$ & 104 & 18 & $17.3^{* * *}$ \\
High dose $\left(\mathrm{G}_{3}\right)$ & 85 & 21 & $24.7^{* * *}$ \\
\hline
\end{tabular}

increase in Average body weight of newborn rats and rate of acquisition in weight at weaning $113.3 \%$ and in rats age 12 weeks, $663.9 \%$ for weight at the beginning of the experiment $(9.8 \pm 0.9 \mathrm{~g})$. And the lack of significant $(P<0.05)$ compared to the control group.

In the group (G3) treatment with high-dose, there is increase in the average body weight of newborn rats 8.5 $\pm 1.6 \mathrm{~g}$ and rate of acquisition in weight is $127.6 \%$ after weaning and $820.4 \%$ and $820.4 \%$ in adult male rats after 12 weeks in respect to the weight of rat neonatal and increased significantly $(P<0.05)$ compared with the con- trol group.

\subsection{Histopothological, Changes in the Adrenal Gland}

The adrenal glands (also known as suprarenal glands) are endocrine glands that sit on top of the kidneys (plate 1); they are surrounded by an adipose capsule and renal fascia. Adrenal gland consists of two parts different in form, function and embryonic origin ate Cortex and medulla, both of which produce hormones.

The cortex mainly produces cortisol, aldosterone, and androgens, while the medulla chiefly produces epinephrine and norepinephrine. The adrenal cortex comprises three zones, or layers. Zona glomerulosa (the outermost layer), Zona fasciculata (situated between the glomerulosa and reticularis) and Zona reticularis (the inner most cortical layer) Figures 1 \& 2.

The adrenal medulla is the core of the adrenal gland, and is surrounded by the adrenal cortex. There are two types of cells. The chromaffin cells of the medulla, named for their characteristic brown staining with chromic acid salts, are the body's main source of the circulating catecholamines adrenaline (epinephrine) and noradrenaline (norepinephrine). Neurons: a multi-polar nerve cells have the same installation of regular neurons (Figure 3).

The present results showed that histologically, picture of the sector in the adrenal gland of newborn rats of the pregnant female treatment with dose low of octyl phenol $\left(G_{2}\right)$ shows that changes in the regions of cortex $(\mathbf{F i}-$ gure 4) and medulla (Figure 5) and was the emergence of areas of decomposition cytoplasmic in cells of the cortex and atrophy of the nuclei, as well as the presence of areas of hemorrhage in the tissue interface and also included these changes pulp area where the bleeding obvious.

The present histological result showed that picture of

Table 3. Body weigh (rang and mean \pm SD) in gram and percent gain in body weight for adult male rats after prental exposure to 4-tert octylephenol and that of control.

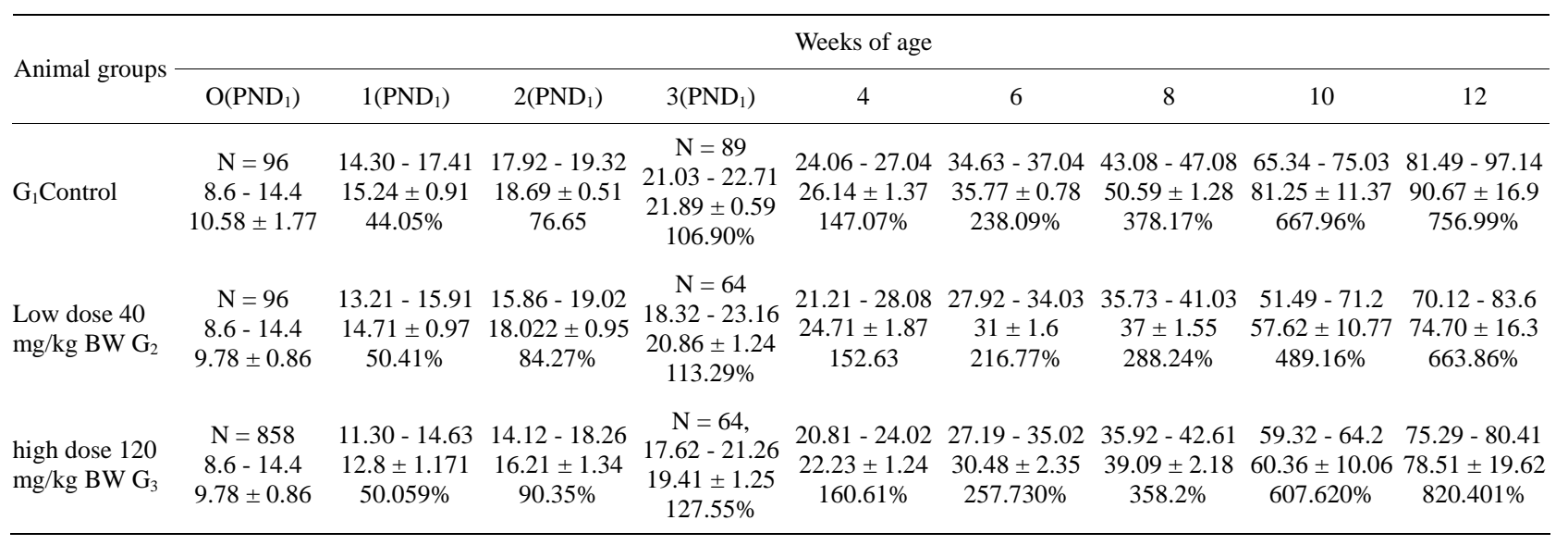




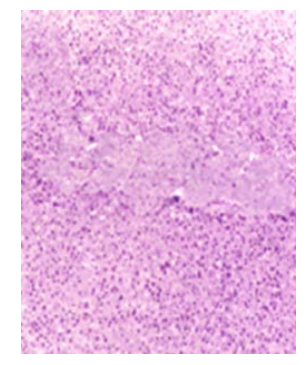

Figure 1. Picture of the sector in the sdrenal cortex of untreated rat.

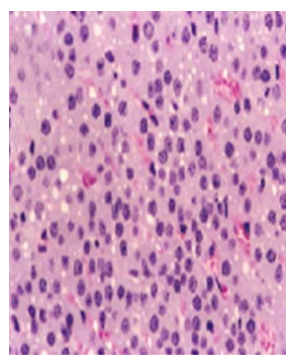

Figure 2. Picture of the sector in the adrenal cortex of untreated rat shows the adrenal cortex comprises three zones, Zona glomerulosa, Zona fasciculata and Zona.

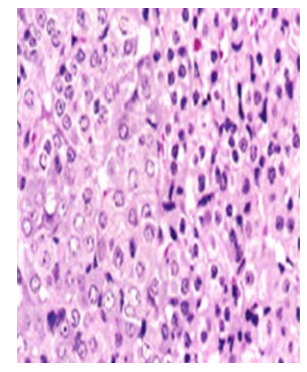

Figure 3. Picture of the sector in the adrenal medulla of untreated rate shows the adrenal medulla is surrounded by the adrenal cortex. There are two types of cells. The chromaffin cells of the medulla, and noradrenaline (norepinephrine).

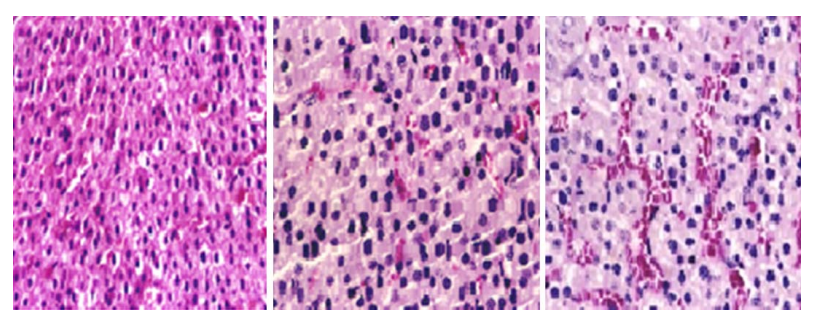

Figure 4. Picture of the sector in the adrenal cortex of new born rats of the pregnant female treatment with dose low of octyl phenol $\left(\mathrm{G}_{2}\right)$ shows that changes in the regions of cortex was the emergence of areas of decomposition cytoplasmic in cells of the cortex as well as the presence of areas of hemorrhage in the tissue interface.

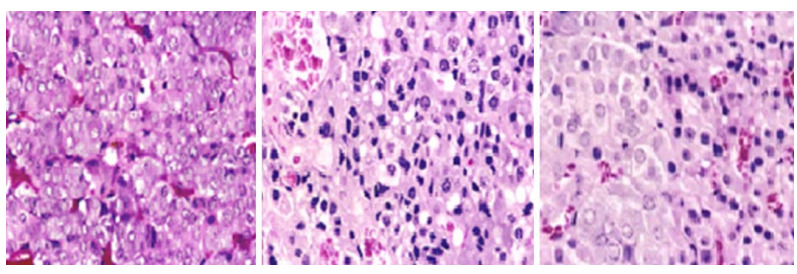

Figure 5. Picture of the sector in the adrenal medulla of new born rats of the pregnant female treatment with dose low of octyl phenol $\left(G_{2}\right)$ shows that changes in the regions of medulla was the emergence of areas of decomposition cytoplasmic of the medulla and also included these changes pulp area where the bleeding.

the sector in the adrenal gland in the group which was given high dose of 4-tert-octyl phenol $\left(\mathrm{G}_{2}\right)$ show that Severe histologic changes in the cortex Where observed cells and nuclei with distorted and viewed the phenomenon of cytoplasmic degradation strongly and necrosis of cells and nuclei Figures 6). When examining medulla and found large areas of necrosis and cell degradation (Figures 7), necrosis and cell death sharply.

\section{DISCUSSION}

The present results showed that there is non-significant in the number and the size of newborn rats of the pregnant female treatment with dose low-and high-4-tertoctyl phenol compared to the control group and did not observe any superficial changes or behavioral on newborns male rats during the period of infancy through adulthood. The present results showed that there signifycantly increased in mortality rate of newborn rats of the pregnant female treatment with dose low-and high4-tertoctyl phenol (during the period of lactation). the observed changes may be early events in the newborn rat that leads to 4-tert-octylphenol (OP) is a prevalent environmental pollutant that effect on the reproductive system seems to be especially vulnerable and, in connection with abnormally high exposures of such hormone disruptors, reproductive processes in animals [1]. Chandana et al., [18] suggest that the exposure of female neonates to OP can interfere with the display of sexual receptive behavior in adulthood. Based on the present SDNPOA data and previous reports, it may be possible to conclude that the OP administered into neonatal female rats might have adversely affected the specific brain regions that are implicated in the regulation of the cyclic release of pituitary gonadotropins and PRL, and the display of sexual behavior. OP is capable of interfering with sexual differentiation of the brain, which normally occurs within the first 2 week of life in rats [19].

The obtained results showed that there is increased in the average body weight and percentage of gain in body weight of male rats from mothers of small treatment (G2, G3) and the control group (G1) for 12 weeks of age. this 


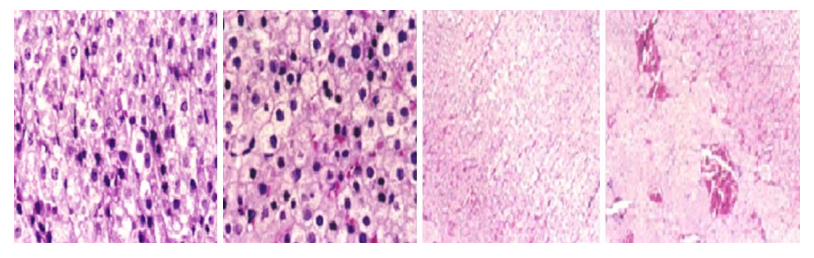

Figure 6. Picture of the sector in the adrenal cortex of new born rats of the pregnant female treatment with dose high of octyl phenol $\left(\mathrm{G}_{2}\right)$ shows that severe histologic changes in the cortex Where observed cells and nuclei with distorted and viewed the phenomenon of cytoplasmic degradation strongly and necrosis of cells and nuclei.

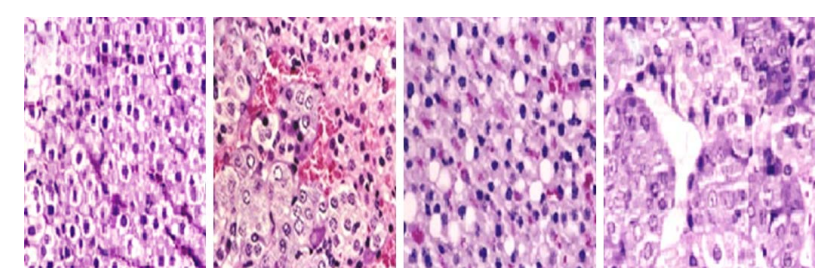

Figure 7. Picture of the sector in the adrenal medulla of adult rats with dose high of octyl phenol $\left(\mathrm{G}_{3}\right)$ shows that large areas of necrosis and cell degradation necrosis and cell death sharply in medulla.

finding is supporting by Yoshida et al. [20] reported that female adult rats exposed to high doses of OP showed a significant suppression of body weight. Whereas Howedshell et al. [21] who found that exposure to an EDC increased postnatal body weight and advanced puberty in female mice. There are varying reports on the effects of endocrine disrupting compounds on body weight. Laws et al. [22] reported that none of the environmental estrogens examined had any significant effects on body weight in rats exposed as adults or during neonatal life. Therefore, from these results we can suggest that OP may be exerting an anabolic estrogenic effect promoting growth in sheep.

It was concluded that the histological results showed that the adrenal gland of newborn rats of the pregnant female treatment with dose low of 4-tert-octyl phenol $\left(G_{2}\right)$ shows that changes in the regions of cortex and medulla and was the emergence of areas of decomposition cytoplasm in cells of the cortex and atrophy of the nuclei, as well as the presence of areas of hemorrhage in the tissue interface and also included these changes pulp area where the bleeding obvious. Also, histological results showed that the adrenal gland in the group which was given high dose of 4-tert-octyl phenol $\left(\mathrm{G}_{2}\right)$ show that Severe histological changes in the cortex. When examining medulla and found large areas of necrosis and cell degradation, necrosis and cell death sharply. The observed harmful effect of 4-OPL on tissue of adrenal gland may be the result of interference with the hormone production by the developing testis. 4-tert-octylphenol (endocrine-active compound) interferes with the growth and steroid hormone synthesis of infant rat testis. It has a high affinity to estrogen receptors, causes a variety of reproductive tract anomalies, and alters androgen status by modifying biosynthesis of sex steroids [23]. OP has been shown to interfere with the development of reproductive system [24]. OP binds to estrogen receptors, but compared to DES, the binding affinity is 5000- to 10,000 fold weaker [25]. In developing rat testis, OP may cause a prolonged suppression of testosterone synthesis [26]. New findings reveal that the mode of action of 4-OPL and other endocrine disruptors in complex and not solely confined to its binding to ER, as shown in mouse Leydig tumor cells cultured with biphenyl A, an anti-androgen, 4-OPL inhibited human chorionic gonadotrophin, stimulated cAMP production, revealing a different mode of action [27]. Actually, one study suggested that OP is directly toxic to spermatogonia and Sertoli cells in culture, exerting its effects through a calcium-independent apoptotic pathway [28]. In male rats, oral ingestion of high concentrations of OP can lead to an increased accumulation of the chemical in various tissues [4], suggesting that these alkylphenolic compounds are capable of bioaccumulation in mammalian cells, and thus, they contribute substantially to the environmental estrogen pool. Sharpe et al. [29] suggesting that also the proliferation of germ cells in the pre-spermatogenic wave is dependent on a certain concentration of testosterone. 4-OPL might interfere with the production of testosterone, and thereby indirectly reduce the proliferation rate of pre-spermatogonia. The effect of OP on reproductive system in the present study might be explained by similar mechanisms. But further investigation is needed to elucidate this. Nevertheless, a significant and harmful effect of OP on adrenal gland tissue compared to the control was clear. However, OP may exert harmful effect in reproductive system, which later on in life may result in reduced fertility. This emphasizes the need for studies on human tissue in order to obtain reliable result in connection with human exposure.

\section{REFERENCES}

[1] Giger, W., Brunner, P.H. and Schaffner, C. (1984) 4-nonylphenol in sewage sludge: Accumulation of toxic metabolites from nonionic surfactants. Science, 225, 623-625. doi:10.1126/science.6740328

[2] White, R., Joblin, S., Hoare, S.A., Sumpter, J.P. and Parker, M.G. (1995) Environmentally persistent alkylphenolic compounds are estrogenic. Endocrinology, 135, 175-182. doi:10.1210/en.135.1.175

[3] Blake, C.A. and Ashiru, O.A. (1997) Disruption of rat estrous cyclicity by the environmental estrogen 4-tertoctylphenol. Proceedings of the Society for Experimental Biology and Medicine, 216, 446-451.

[4] Certa, H., Fedtke, N., Wiegand, H.-T. and Muller, A.M.F. 
(1996) Toxicokinetics of p-tert-octylphenol in male Wistar rats. Archives Toxicology, 71, 112-122.

doi:10.1007/s002040050365

[5] Guillette, L.J. Jr, Gross, T.S., Masson, G.R. and Matter, J.M. (1994) Developmental abnormalities of the gonad and abnormal sex hormone concentrations in juvenile alligators from contaminated and control lakes in Florida. Environmental Health Perspectives, 102, 680-688. doi:10.1289/ehp.94102680

[6] Colborn, T., Von Saal, F.S. and Soto, A.M. (1993) Developmental effects of endocrine-disrupting chemicals in wildlife and humans (see comments). Environmental Health Perspectives, 101, 378-384. doi:10.1289/ehp.93101378

[7] Fisher, R.M., Millar, J.S., Jobling, M.M. and Sumpter, J.P. (1995) Gestational and lactational exposure of rats to xenoestrogens results in reduced testicular size and sperm production. Environmental Health Perspectives, 103, 11361143. doi:10.1289/ehp.951031136

[8] Jobling, S., Sheahan, D.A., Osborne, J.A., Matthiessen, P. and Sumpter, J.P. (1995) Inhibition of testicular growth in rainbow trout (Oncorhynchus mykiss) exposed to invironmental estrogens. Environmental Toxicology Chemistry, 15, 194-202.

[9] Laws, S.C., Carey, S.A., Ferrell, J.M., Bodman, G.J. and Cooper, R.L. (2000) Estrogenic activity of octylphenol, nonylphenol, bisphenol A and methoxychlor in rats. Toxicology Science, 54, 154-167. doi:10.1093/toxsci/54.1.154

[10] Katsuda, S., Yoshida, M., Watanabe, G., Taya, K. and Maekawa, A. (2000) Irreversible effects of neonatal exposure to p-tert-octylphenol on the reproductive tract in female rats. Toxicology and Applied Pharmacology, 165, 217-226. doi:10.1006/taap.2000.8940

[11] Nagao, T., Saito, Y., Usumi, K., Nakagomi, M., Yoshimura, S. and Ono, H. (2000) Disruption of the reproductive system and reproductive performance by administration of nonylphenol to newborn rats. Human \& Experimental Toxicology, 19, 284-296. doi:10.1191/096032700678815909

[12] Nagao, T., Yoshimua, S., Saito, Y., Nakagomi, M., Usumi, K. and Ono, H. (2001) Reproductive effects in male and female rats of neonatal exposure to Genistein. Reproductive Toxicology, 15, 399-411. doi:10.1016/S0890-6238(01)00141-1

[13] Nagao, T., Yoshimura, S., Saito, Y., Nakagomi, M., Usumi, K. and Ono, H. (2001) Reproductive effects in male and female rats from neonatal exposure to p-octylphenol. $R e$ productive Toxicology, 15, 683-692. doi:10.1016/S0890-6238(01)00173-3

[14] Mueller, G.C. and Kim, U.H. (1978) Displacement of estradiol from estrogen receptors by simple alkyl phenols. Endocrinology, 102, 1429-1435. doi:10.1210/endo-102-5-1429

[15] Jobling, S. and Sumpter, J.P. (1993) Detergent components in sewage effluent are weakly oestrogenic to fish: An in vitro study using rainbow trout (Oncorhynchus mykiss) hepatocytes. Aquatic Toxicology, 27, 361-372. doi:10.1016/0166-445X(93)90064-8

[16] De Jager, C., Bornman, M.S., Wandrag, S. and Sharpe,
V.W. (2001) The lethal dose and potential reproductive effect of P. nonylphenol in rats: A prilimanary study. Arch Andrology, 46, 183-187.

[17] Bancroft, J.D. and Stevens, A. (1977) Theory and practice of histological techniques. Longman Inc., New York, 240.

[18] Chandana, B.H., Gen, W., Shin-Ichi, K., Midori, Y., Akira, K.S.K.T. (1994) Exposure of neonatal female rats to p-tertoctylphenol disrupts afternoon surges of luteinizing hormone, follicle-stimulating hormone and prolactin secretion, and interferes with sexual receptive behavior in adulthood. Water Research, 28, 1143-1152.

[19] Sharpe, R.M., Rivas, A., Walker, M., McKinnell, C. and Fisher, J.S. (2003) Effect of neonatal treatment of rats with potent or weak (environmental) oestrogens, or with a GnRH antagonist, on Leydig cell development and function through puberty into adulthood. International Journal of Andrology, 26, 26-36. doi:10.1046/j.1365-2605.2003.00385.x

[20] Yoshida, M., Katsuda, S., Ando, J., Kuroda, H., Takahashi, M. and Maekawa, A. (2000) Subcutaneous treatment of p-tert-octylphenol exerts estrogenic activity on the female reproductive tract in normal cycling rats of two different strains. Toxicology Letters, 116, 89-101. doi:10.1016/S0378-4274(00)00207-1

[21] Howdeshell, K.L., Hotchkiss, A.K., Thayer, K.A., Vandenbergh, J.G., Vom Saal, F.S. (1999) Exposure to bisphenol A advances puberty. Nature, 401, 763-764. doi:10.1038/44517

[22] Laws, S.C., Carey, S.A., Ferrell, J.M., Bodman, G.J. and Cooper, R.L. (2000) Estrogenic activity of octylphenol, nonphenol, bisphenol A, and methoxychlor in rats. Toxicology Science, 54, 154-167.

[23] Majdic, G., Sharpe, R.M., Shaughnessy, P.J., et al. (1996) Expression of cytochrome P450 17 alpha-hydroxylase/ C17-20 lyase in the fetal rat testis is reduced by maternal exposure to exogenous estrogens. Endocrinology, 137, 10631070.

[24] Sweeney, T., Nicol, L., Roche, J.F., et al. (2000) Maternal exposure to octylphenol suppresses ovine fetal folliclestmulating hormone secretion, testis size, and Sertoli cell number. Endocrinology, 141, 2667-2673. doi:10.1210/en.141.7.2667

[25] Gutendorf, B. and Westendorf, J. (2001) Comparison of an array of in vitro assays for the assessment of the estrogenic potential of natural and synthetic estrogens, phytoestrogens and xenoestrogens. Toxicology, 166, 79-89. doi:10.1016/S0300-483X(01)00437-1

[26] Yoshida, M., Katsuda, S., Takenaka, A., Watanabe, G., Taya, K. and Maekawa, A. (2001) Effects of neonatal exposure to a high-dose p-tertoctylphenol on the male reproductive tract in rats. Toxicology Letters, 121, 21-33. doi:10.1016/S0378-4274(01)00311-3

[27] Nikula, H., Talonpoika, T., Kaleva, M., et al. (1999) Inhibition of hCG-stimulated steroidogenesis in cultured mouse Leydig tumor cells by bisphenol A and octylphenols. Toxicology Applied Pharmacology, 157, 166-173. doi:10.1006/taap.1999.8674

[28] Raychoudhury, S.S., Blake, C.A. and Millette, C.F. (1999) 
Toxic effects of octylphenol on cultured rat spermatogenic cells and Sertoli cells. Toxicology Applied Pharmacology, 157, 192-202. doi:10.1006/taap.1999.8664

[29] Sharpe, R.M., Atanassova, A., McKinnell, C., Parte, P., Turner, K.J., et al. (1998) Abnormalities in functional development of the Sertoli cells in rats treated neonatally with diethylstilbestrol: A possible role for estrogens in Sertoli cell development. Biology of Reproduction, 59, 1084-1094. doi:10.1095/biolreprod59.5.1084 